\title{
Investigating the Influence of Knowledge Management Practices on Organizational Performance: An Empirical Study
}

\author{
Mohamad H. Gholami ${ }^{1}$, Mehrdad Nazari Asli ${ }^{2}$, Salman Nazari- \\ Shirkouhi $^{3^{*}}$, Ali Noruzy ${ }^{4}$
}

${ }^{1}$ Department of Industrial Engineering \& Management Systems, Amirkabir

University of Technology, Tehran, Iran, P.O. Box: 15977-37615

E-mail: fgholami@aut.ac.ir

${ }^{2}$ Department of Management, Imam Khomeini International University, Qazvin, Iran, P.O. Box: 34149-16818, E-mail: akimiaee@mohaddes.ac.ir

3,* Young Researchers Club, Roudbar Branch, Islamic Azad University, Roudbar, Iran, P.O. Box 14579-44616, E-mail: snnazari@ut.ac.ir; corresponding author

${ }^{4}$ Department of Educational Administration, Faculty of Psychology and Education, University of Tehran, Tehran, Iran, P.O. Box 11365-4563

E-mail: ali.noruzy@ut.ac.ir

\begin{abstract}
The aim of this study is to investigate the influence of knowledge management practices on organizational performance in small and medium enterprises (SMEs) using structural equation modeling (SEM). A number of 282 senior managers from these enterprises were chosen using simple random sampling and the data were analyzed with the structural equation model. The results showed that knowledge acquisition, knowledge storage, knowledge creation, knowledge sharing, and knowledge implementation have significant factor loading on knowledge management; and also productivity, financial performance, staff performance, innovation, work relationships, and customer satisfaction have significant factor loading on organizational performance. Finally, the results of this study suggest that knowledge management practices directly influence the organizational performance of SMEs.
\end{abstract}

Keywords: knowledge management; organizational performance; SMEs

\section{Introduction}

Today's necessity of information and development of knowledge in the organizations and the acceptance of the human resources managers' role as knowledge managers has become the vision of the organizations which are 
interested in keeping their competitive advantage. KM helps the SMEs have a proper understanding of and insight into their internal experiences and external resources (customers, suppliers, and competitors). KM activities, including knowledge acquisition, knowledge storage, knowledge creation, knowledge sharing and knowledge implementation can help the SMEs achieve necessary capabilities, such as problem solving, dynamic learning, strategic planning, decision-making, and improving their organizational performance as a whole[1]. The main goal of $\mathrm{KM}$ is the rapid, effective and innovative utilization of the resources and knowledge assets, infrastructures, processes and technologies in order to promote organizational performance [2].

Many researchers have attempted to explain why certain firms behave better than others by linking different organizational elements with performance measures. These studies include linking performance with strategy, structure, environment, learning capabilities, market orientation, resources, and employees' abilities [3]. As $\mathrm{KM}$ involves valuable processes which can influence the productivity, financial performance, staff performance, innovation, work relationships and customer satisfaction and finally organizational performance, studying the influence of KM practices on organizational performance in SMEs is important [4]. However, studying KM practices in the SMEs has not been sufficiently considered in literature, and limited studies have been conducted o investigate the effect of KM practices on their organizational performance. SMEs can achieve a higher degree of productivity, innovation, efficiency, customer satisfaction and competitive advantage with the use of KM practices, with the result finally of in improvement in organizational performance [5].

\section{Knowledge Management Practices and Organizational Performance}

$\mathrm{KM}$ practices means the process of acquiring, storing, understanding, sharing, implementing knowledge, and these actions are taken in the organizational learning process with regard to the culture and strategies of the organizations [6]. On the other hand, Bhatti and Qureshi [7] stated that KM means efforts to explore the tacit and explicit knowledge of individuals, groups, and organizations and to convert this treasure into organizational assets so that individuals and managers can use it in various levels of decision making. KM is a systematic and integrated management strategy that develops, transfers, transmits, stores, and implements knowledge so that it can improve efficiency and effectiveness of the organization's manpower [8].

The relevant theory that helps significantly towards realizing the important role of knowledge management is the knowledge-based theory. This theory supposes that knowledge management practices such as knowledge acquisition, knowledge 
storage, knowledge creation, knowledge sharing and knowledge implementation play a critical role in achieving high level productivity, financial and human resource performance and finally improving sustainable competitive advantage $[9$, 10].

In order for SMEs to be more successful and survive in a competitive market, they need to consider adaptive and intelligent strategies, including KM processes and best practices [11, 12].Some scholars have developed conceptual models based on knowledge-based theory which contain critical KM practices. On the other hand, $\mathrm{KM}$ practices could be defined in various forms and utilized in different configuration. For example, the life cycle model by Nissen et al. [13] divided a knowledge flow into six phases. These six phases are creation, organization, formalization, distribution, application or implementation, and evolution. Moreover, Wiig et al. [14] described KM as including eight practices: reviewing, analyzing the KM processes, analyzing the application risks, executing the proposed plans, developing knowledge, consolidating knowledge, sharing knowledge, and combining knowledge.

As discussed in the research background, different models are considered to describe KM practices in various ways. In this research, five main practices are adapted from the models of Nonaka et al. [15], Dahiya et al. [8] and Bhatti and Qureshi [7]. These practices encompass knowledge creation, acquisition, sharing, storage, and implementation, which have been frequently applied in evaluation of KM practices.

Knowledge creation: Knowledge creation involves the utilization of internal and external resources of an organization to generate new knowledge for achieving the organizational goals. Brainstorming methods and conducting research to make the best use of the knowledge assets of customers, suppliers and staffs are strategies applied in many prosperous SMEs for creating knowledge [16].

Knowledge Acquisition: This practice encompass the process of acquiring and learning appropriate knowledge from various internal and external resources, such as experiences, experts, relevant documents, plans and so forth. Interviewing, laddering, process mapping, concept mapping, observing, educating and training are the most familiar techniques for knowledge acquisition.

Knowledge sharing: Knowledge sharing is a process through which personal and organizational knowledge is exchanged. In the other words, knowledge sharing refers to the process by which knowledge is conveyed from one person to another, from persons to groups, or from one organization to other organization [17].

Knowledge storage: Knowledge storage involves both the soft or hard style recording and retention of both individual and organizational knowledge in a way so as to be easily retrieved. Knowledge storage utilizes technical systems such as modern informational hardware and software and human processes to identify the knowledge in an organization, then to code and index the knowledge for later 
retrieval [18]. In the other words, organizing and retrieving organizational knowledge means knowledge storage by providing the ability to retrieve and use the information by the individuals.

Knowledge implementation: This means the application of knowledge and the use of the existing knowledge for decision-making, improving performance and achieving goals. Organizational knowledge should be implemented in the services, processes and products of the organization.

Organizational performance is one of the most important structures discussed in management research and could be considered as the most important criterion for testing the success of SMEs. Performance is one of the most critical areas of SME management, which many management scholars and practitioners have focused on improving via strategic variables such as KM practices [3]. Past studies have conceptualized firms' performance with measures of return on assets, sales growth, new product success [19], market share and overall performance [20], sales growth, market share and profitability [21], overall performance, new product success, change in relative market share [22], profitability, sales growth, and overall customer satisfaction [23]. In this field, Venkatraman and Ramanujam [24] found that financial measures (return on equity, return on investment) and operational measures (market share, sales growth, and, profit growth) were frequently employed to measure organizational performance. On the other hand, there is no full consensus among academic researchers on the variables and indices of organizational performance. In the other words, organizational performance indices are different in SMEs. Researchers have considered different indices for the assessment of the performance of SMEs. For example, Johnsen and McMahon [25] considered return on assets, return on shareholders' salary, and return on investment and dividend as the performance indices of SMEs. Koh et al. [26] used three criteria to measure organizational performance, including organizational effectiveness (the relative quality of the products, success in the provision of new products, and the ability of the organization to keep the customers), share and growth of market (sales levels, sales growth, and relative market share), and profitability (capital return rate and profit margin). In addition, Huang [27] considered the indices of effectiveness, efficiency, productivity, life quality, innovation, and profitability for measuring the organizational performance of SMEs. Since the considered indices for measuring performance of the SMEs are different, some of the most important indices applied in previous researches have been selected for this study. The indices which are considered here for measuring the performance of these enterprises include productivity, financial performance, staff performance, innovation, work relationships and customer satisfaction.

Customer satisfaction is an essential component for the survival of the firm, and firms that are responsive to changes in customer needs, requirements and wants are expected to achieve a sustainable competitive advantage [28]. Additionally, innovation can be considered as a critical factor in achieving high performance. 
Innovation is about using technology and knowledge to offer customers a new product or service via improved features or lower prices [29].

These six indices are of the highest importance in measuring the performance of SMEs, and few studies have been done on effect of KM activities on organizational performance [30]. However, a few researchers have been able to identify KM practices and relate them to the firm's performance. Some research indicates that firms which use suitable KM practices might enhance their capabilities, which may in turn result in better firm performance [1, 31, 32, 33].

Roland [34] in his study indicated that performance depends on a firm's ability to integrate knowledge into the value creation process and into core competency based strategies. Furthermore, his findings revealed that to achieve and maintain a high level of performance, an organization must develop efficient mechanisms for creating, transferring, and integrating knowledge. Also, Noruzy et al. [35] conducted research to study the influence of $\mathrm{KM}$ on organizational performance among 106 companies. Their results showed that KM positively influences the organizational performance of manufacturing firms. Moreover, Garcia-Morales et al. [30] suggested that strategic variables of knowledge (knowledge slack, absorptive capacity, tacitness) play a positive mediating role between transformational leadership and organizational performance.

Furthermore, Zack et al. [1] revealed that KM practices have a positive and indirect influence on financial performance. Also, Kiessling et al. [6] suggested that KM positively affects organizational outcomes, such as the firm's innovation, product improvement and employee improvement. Other research has indicated that KM positively and directly influences the SMEs' organizational performance [5, 36, 37] (Fugate et al., 2009; Chen and Liang, 2011; Hussain et al., 2011). According to the reviewed literature, we propose the following hypothesis:

Hypothesis: Knowledge management practices positively influence organizational performance.

\section{Methods}

\subsection{Sample and Procedure}

The statistical population of this study consists of SMEs in Iran within the food industries, auto industries, textile industries, pipe and faucet industries, electronic industries, and clothing industries. Three hundred and eighty questionnaires were distributed among the sample group. All of the questionnaires were distributed during one month. A preliminary survey instrument was pre-tested by 30 senior managers and the reliability of the instrument estimated by using Cronbach's Alpha. Results with Cronbach's Alpha showed that the instruments had acceptable 
reliability (more than 0.7). Finally, a total of 282 completed questionnaires were obtained.

\subsection{Instruments}

Knowledge management practices: The knowledge management practices instrument was adapted from Cho [3], Chen and Huang [38], Chen and Liang [36], and Fugate et al. [5]. This questionnaire consists of five components included: knowledge acquisition, knowledge storage, knowledge creation, knowledge sharing and knowledge implementation. A five point Likert scale was used to measure these components (strongly disagree $=1$, to strongly agree $=5$ ). The validity and reliability was confirmed using a confirmatory factor analysis $(\chi 2 / \mathrm{df}=1.26, \mathrm{RMSEA}=0.036, \mathrm{NFI}=0.91, \mathrm{NNFI}=0.90, \mathrm{CFI}=90)$ and Cronbach's Alpha ( $\alpha=0.81,0.78,0.73,0.84$ and 0.85 for each components). Results showed that our scale has high validity and reliability.

Organizational performance: For measuring the organizational performance we developed a scale by adapting some items from previous studies, such as Cho et al. [39]; Chen and Liang [36] and Fugate et al. [5]. This scale consists of five components included: productivity, financial performance, staff performance, innovation, work relationships and customer satisfaction. A five point Likert scale was used to measure these components (strongly disagree $=1$, to strongly agree $=5$ ). To examine its validity and reliability we performed confirmatory factor analysis $(\chi 2 / \mathrm{df}=1.3, \mathrm{RMSEA}=0.069, \mathrm{NFI}=0.93, \mathrm{NNFI}=0.90, \mathrm{CFI}=90)$ and Cronbach's Alpha $(\alpha=0.71,0.75,0.82,0.80,0.69$ and 0.85 for each components respectively).The results showed that this scale has high validity and reliability for measuring organizational performance.

\section{Findings}

Structural equation modeling (SEM) was conducted to estimate the fitness of the model, and to perform the SEM analysis the LISREL 8.30 program was used. The most practical indices were used to estimate the model fitness, including: $\chi 2 / d f$, Root Mean Square Error of Approximation (RMSEA), Goodness of Fit Index (GFI), Comparative Fit Index (CFI) and Adjusted Goodness of Fit Index (AGFI).Scores lower than 5 for the $\chi 2 / \mathrm{df}$ index reveals an acceptable rate; in other words, smaller scores in this index indicate a better fitness of the model $[40,41]$. In this study, the $\chi 2 / \mathrm{df}$ was 1.051 , which attests to the appropriate fitness of the model. An RMSEA equal to or lower than 0.05 is suitable for tested models, but scores above 0.05 and up to 0.08 propose an agreeable error of approximation in the model. Models with their RMSEA at 0.10 and higher are considered to have low fitness. GFI and AGFI show to what degree the model has 
better fitness when compared to the model's non-existence. For the model to be acceptable, GFI, AGFI and CFI should be equal to or higher than 0.90 [40].

Figure 1 shows the factor loading of KM components (knowledge acquisition, knowledge storage, knowledge creation, and knowledge sharing and knowledge implementation) and organizational performance components (productivity, financial performance, staff performance, innovation, work relationships and customer satisfaction). As this figure shows, KM practices in SMEs significantly and positively influenced organizational performance $(\beta=0.41)$.

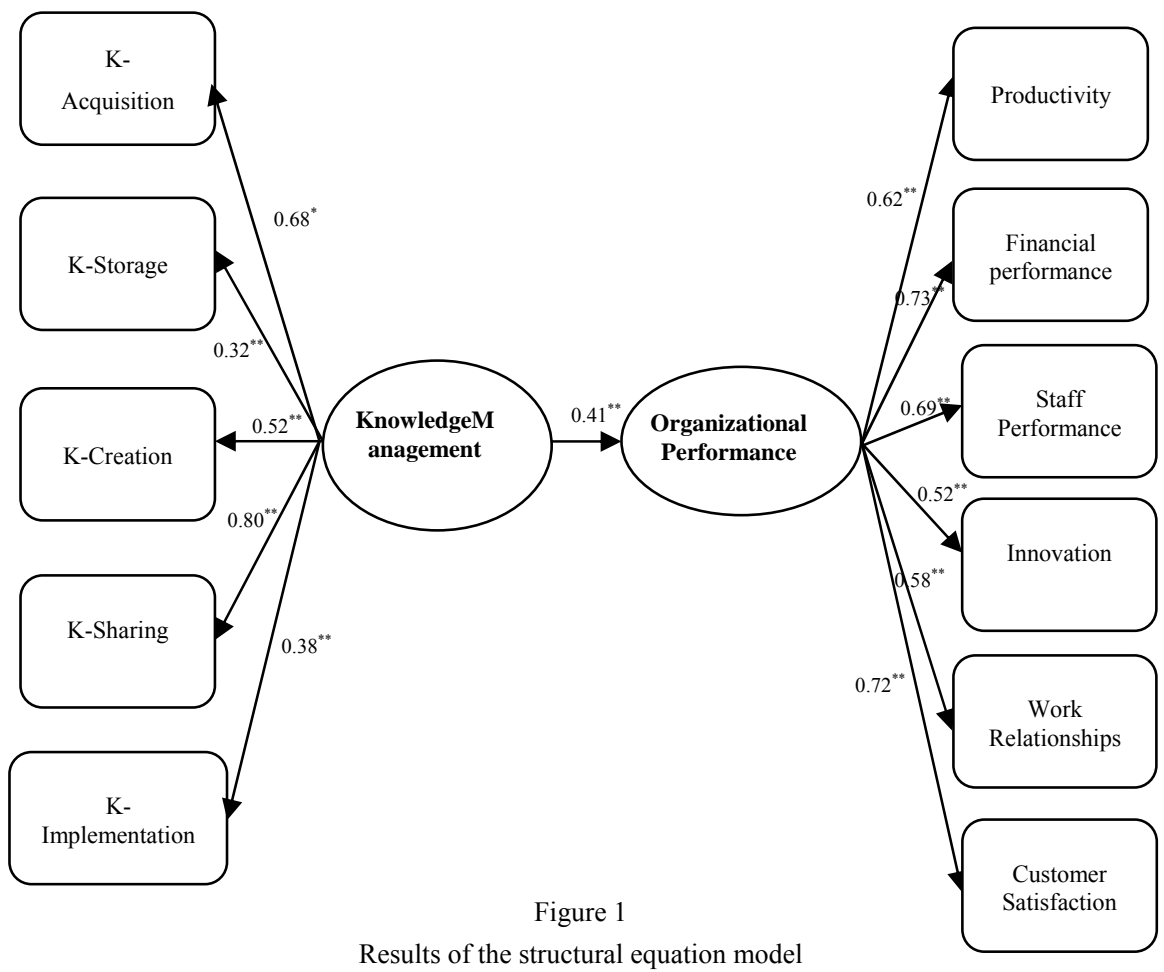

The results of Table 1 indicate scores of factor loadings and explain variances for KM practices and organizational performance. Factor loadings for knowledge acquisition, knowledge storage, knowledge creation, knowledge sharing and knowledge implementation are $0.68,0.32,0.52,0.80$, and 0.38 , respectively. These factor loadings are statistically significant $(\mathrm{p}<0.01)$. Moreover factor loadings for productivity, financial performance, staff performance, innovation, work relationships and customer satisfaction are $0.62,0.73,0.69,0.52,0.58$ and 0.72 , respectively, while the explained variances for these variables are $0.46,0.53$, $0.47,0.27,0.33$ and 0.51 . These factor loadings are statistically significant at $\mathrm{P}<0.01$. 
Table1

Factor loadings and estimated common variance of the variables

\begin{tabular}{|l|c|c|c|c|}
\hline \multirow{2}{*}{ Variable } & \multicolumn{2}{|c|}{ Knowledge Management } & \multicolumn{2}{c|}{ Organizational Performance } \\
\cline { 2 - 5 } & $\begin{array}{c}\text { Factor } \\
\text { Loading }\end{array}$ & $\begin{array}{c}\text { Explained } \\
\text { Variance }\end{array}$ & $\begin{array}{c}\text { Factor } \\
\text { Loading }\end{array}$ & $\begin{array}{c}\text { Explained } \\
\text { Variance }\end{array}$ \\
\hline Knowledge Acquisition & 0.68 & 0.46 & & \\
Knowledge Storage & 0.32 & 0.10 & & \\
Knowledge Creation & 0.52 & 0.27 & & \\
Knowledge Sharing & 0.80 & 0.64 & & \\
Knowledge Implementation & 0.38 & 0.14 & 0.68 & 0.46 \\
Productivity & & & 0.73 & 0.53 \\
Financial performance & & & 0.69 & 0.47 \\
Staff Performance & & 0.52 & 0.27 \\
Innovation & & 0.58 & 0.33 \\
Work Relationships & & 0.72 & 0.51 \\
Customer Satisfaction & & & & \\
\hline
\end{tabular}

Moreover, KM practices in SMEs positively influenced organizational performance $(\beta=0.41)$, the $\beta$ of which is statistically significant $(p<0.01)$. Table 2 shows the goodness of fit indices for the estimated model. As can be seen, the $\chi 2 / \mathrm{df}$ score is 2.1 , which lies within the acceptable range. Additionally, the RMSEA score is 0.064 , which is lower than 0.08 , and is thus within the acceptable range. The scores for AGFI, GFI and CFI, which are 0.90, 0.91 and 0.91, respectively, reveal the acceptability of these scores for the model. In total, one can say the examined model has an appropriate fitness.

Table 2

Goodness of fit indices for the second-rank model

\begin{tabular}{cccccc}
\hline Model & $\chi^{2} / \mathrm{df}$ & RMSEA & GFI & AGFI & CFI \\
Scores & 2.1 & 0.064 & 0.91 & 0.90 & 0.91 \\
\hline
\end{tabular}

\section{Discussion and Conclusion}

As discussed in previous sections, KM encompasses knowledge acquisition, knowledge storage, knowledge creation, knowledge sharing, and knowledge implementation, and organizational performance includes critical components such as productivity, financial performance, staff performance, innovation, work relationships, and customer satisfaction. By considering these components, the research model has been conceptualized and operationalized among SMEs. Results showed that knowledge sharing has higher factor loading compared with other KM practices, and financial performance has higher factor compared with other organizational performance components. Other results showed that the SMEs' KM practices positively and significantly influenced their organizational performance. Generally, based on our findings, we can say that the improvement of KM practices can play a significant role in improving productivity, financial performance, staff performance, innovation, work relationships, and customer satisfaction, and thus in improving the SMEs' organizational performance [25, 26]. Moreover, the conclusions of this research suggest that KM practices are the critical elements for promoting the performance of SMEs. 
When knowledge is recognized, acquired, and stored, SMEs can implement this knowledge to explore problems and create solutions, producing a structure for facilitating efficiency and effectiveness. In the modern dynamic and complex environment, SMEs need to acquire, create, share, save and implement new knowledge in order to make strategic decisions that can lead to improvements in productivity, financial and staff performance, innovation, work relationships, and customer satisfaction. Thus, SME managers should be committed to providing a supportive climate and culture, one that motivates employees and supervisors to implement the mentioned KM practices, in order to foster the SMEs results.

\section{Managerial Implications}

This research makes a contribution by providing SMEs with better insights into KM practices, including knowledge acquisition, storage, creation, sharing, and implementation, in order to improve organizational performance. Further, by linking these issues to performance, this study demonstrates the importance of KM for better firm performance. Moreover, SME managers should perceive the benefits of $\mathrm{KM}$ practices that can increase productivity, financial performance, staff performance, innovation, work relationships, and customer satisfaction. KM leadership in SMEs should invest in internal and external resources in employing of an appropriate knowledge. Therefore, improved performance can be one of the longterm and strategic benefits of fulfilling KM best practices. SME managers should properly change the workplace culture and environmental circumstances so that employees adopt, support, commit to, and employ KM practices in fulfilling their activities.

SMEs could easily collect information from their customers, suppliers and other stakeholders, organize the collected knowledge through modern informational technologies or even traditional means, share the organized knowledge throughout all organizational levels, and finally implement the shared knowledge to overcome challenges and improve performance. Therefore, integrating $\mathrm{KM}$ practices as a strategic element is one of the most important tasks of SME managers.

\section{References}

[1] Zack, M., McKeen, J., and Singh, S. (2009) Knowledge Management and Organizational Performance: an Exploratory Analysis. Journal of Knowledge Management, 13(6), 392-409

[2] Darroch, J. (2005) Knowledge Management, Innovation, and Firm Performance. Journal of Knowledge Management, 9(3), 101-115

[3] Cho, J. K. J. (2001) Firm Performance in the e-commerce Market: the Role of Logistics Capabilities and Logistics Outsourcing. University of Arkansas

[4] Chang, S., and Lee, M. (2008) The Linkage between Knowledge Accumulation Capability and Organizational Innovation. Journal of Knowledge Management, 12(1), 3-20 
[5] Fugate, B. S., Stank, T. P., \& Mentzer, J. T. (2009) Linking Improved Knowledge Management to Operational and Organizational Performance. Journal of Operations Management, 27(3), 247-264

[6] Kiessling, T. S., Richey, R. G., Meng, J., and Dabic, M. (2009) Exploring Knowledge Management to Organizational Performance Outcomes in a Transitional Economy. Journal of World Business, 44(4), 421-433

[7] Bhatti, K. K., and Qureshi, T. M. (2007) Impact of Employee Participation on Job Satisfaction, Employee Commitment and Employee Productivity. International Review of Business Research Papers, 3(2), 54-68

[8] Dahiya, D., Gupta, M., and Jain, P. (2012) Enterprise Knowledge Management System: A Multi Agent Perspective. Information Systems, Technology and Management, 285(4), 271-281

[9] Soderberg, A. M., and Holden, N. (2002) Rethinking Cross Cultural Management in a Globalizing Business World. International Journal of Cross Cultural Management, 2(1), 103-121

[10] Spender, J. C. (1996) Making Knowledge the Basis of a Dynamic Theory of the Firm. Strategic Management Journal, 17(Special Issue), 45-62

[11] Davenport, T., and Prusak, L. (2000) Working Knowledge: How Organizations Manage What They Know. Boston: Harvard Business School Press

[12] Tiwana, A. (2003) The Knowledge Management Toolkit: Orchestrating IT, Strategy, and Knowledge Platforms ( $2^{\text {nd }}$ ed.) Upper Saddle River, NJ: Prentice-Hall

[13] Nissen, M., Kamel, M. N., and Sengupta, K. C. (2000) Integrated Analysis and Design of Knowledge Systems and Processes. Information Resources Management Journal, 13(1), 24-43

[14] Wiig, K. M., DeHoog, R., and Vander Spek, R. (1997) Supporting Knowledge Management: A Selection of Methods and Techniques. Expert Systems with Applications, 13(1), 15-27

[15] Nonaka, I., Umemoto, K., and Senoo, D. (1996) From Information Processing to Knowledge Creation: a Paradigm Shift in Business Management. Technology in Society, 18(2), 203-218

[16] Moodysson, J. (2008) Principles and Practices of Knowledge Creation: On the Organization of "Buzz" and "Pipelines" in Life Science Communities. Economic Geography, 84(4), 449-469

[17] Frappaolo, C. (2006) Knowledge Management. West Sussex, England: Capstone Publishing

[18] Karadsheh, L., Mansour, E., Alhawari, S., Azar, G., and El-Bathy, N. (2009) A Theoretical Framework for Knowledge Management Process: 
towards Improving Knowledge Performance. Journal of Communications of the IBIMA, 7(1), 67-79

[19] Narver, J. C., and Slater, S. F. (1990) The Effect of a Market Orientation on Business Profitability. The Journal of Marketing, 54(3), 20-35

[20] Jaworski, B. J., and Kohli, A. K. (1993) Market Orientation: Antecedents and Consequences. The Journal of marketing, 75(3), 53-70

[21] Deshpande, R., Farley, J. U., \& Webster Jr, F. E. (1993) Corporate Culture, Customer Orientation, and Innovativeness in Japanese Firms: a Quadrad Analysis. The Journal of Marketing, 57(1), 23-37

[22] Baker, W. E., and Sinkula, J. M. (1999) The Synergistic Effect of Market Orientation and Learning Orientation on Organizational Performance. Journal of the Academy of Marketing Science, 27(4), 411-427

[23] Ellinger, A. E., Daugherty, P., \& Keller, S. (2000) The Relationship between Marketing/Logistics Interdepartmental Integration and Performance in U.S. Manufacturing Firms: An Empirical Study. Journal of Business Logistics, 21(1), 112-128

[24] Venkatraman. N., and VasudevanRamanujam (1986) Measurement of Business Performance in Strategy Research: A Comparison of Approaches. Academy of Management Review, 11(4), 60-75

[25] Johnsen, G. J., and McMahon, R. G. P. (2005) Owner-Manager Gender, Financial Performance and Business Growth Amongst SMEs from Australia's Business Longitudinal Survey. International Small Business Journal, 23(2), 115-142

[26] Koh, S. C. L., Demirbag, M., Bayraktar, E., Tatoglu, E., and Zaim, S. (2007) The Impact of Supply Chain Management Practices on Performance of SMEs. Industrial Management \& Data Systems, 107(1), 103-124

[27] Huang, T. C. (2001) The Relation of Training Practices and Organizational Performance in Small and Medium Size Enterprises. Education+ Training, 43(8/9), 437-444

[28] Griffa, A. F. (2008) A paradigm Shift for Inspection: Complementing Traditional CMM with DSSP Innovation. Sensor Review, 28(4), 334-341

[29] Halliday, S. V. (2008) The Power of Myth in Impeding Service Innovation. Journal of Management Inquiry, 17(1), 44-55

[30] Garcia-Morales, V. J., Llorens-Montes, F. J., and Verdu-Jover, A. J. (2008) The Effects of Transformational Leadership on Organizational Performance through Knowledge and Innovation. British Journal of Management, 19(4), 299-319 
[31] Lee, H., and Choi, B. (2003) Knowledge Management Enablers, Processes, and Organizational Performance: An Integrative View and Empirical Examination. Journal of Management Information Systems, 20(1), 179-228

[32] Gloet, M., and Terziovski, M. (2004) Exploring the Relationship between Knowledge Management Practices and Innovation Performance. Journal of Manufacturing Technology Management, 15(5), 402-409

[33] Marques, D. P., and Simon, F. J. G. (2006) The Effect of Knowledge Management Practices on Firm Performance. Journal of Knowledge Management, 10(3), 143-156

[34] Roland, N. (2006) Knowledge Management in the Business-driven Action Learning Process. Journal of Management Development, 25(9), 896-907

[35] Noruzy, A., Dalfard, V., Azhdari, B., Nazari-Shirkouhi, S., and Rezazadeh, A. (2012) Relations between Transformational Leadership, Organizational Learning, Knowledge Management, Organizational Innovation, and Organizational Performance: an Empirical Investigation of Manufacturing Firms. The International Journal of Advanced Manufacturing Technology, in press, $1-13$

[36] Chen, D. N., and Liang, T. P. (2011) Knowledge Evolution Strategies and Organizational Performance: A Strategic Fit Analysis. Electronic Commerce Research and Applications, 10(1), 75-84

[37] Hussain, I., Xiaoyu, Y. U., Si, L. W. S., and Ahmed, S. (2011) Organizational Knowledge Management Capabilities and Knowledge Management Success (KMS) in Small and Medium Enterprises (SMEs) African Journal of Business Management, 5(22), 8971-8979

[38] Chen, C. J., and Huang, J. W. (2009) Strategic Human Resource Practices and Innovation Performance-The Mediating Role of Knowledge Management Capacity. Journal of Business Research, 62(1), 104-114

[39] Cho, J. J., Ozment, J., and Sink, H. (2008) Logistics Capability, Logistics Outsourcing and Firm Performance in an e-commerce Market. International Journal of Physical Distribution \& Logistics Management, 38(5), 336-359

[40] Browne, M. W., and Cudeck, R. (1993) Alternative Ways of Assessing Model Fit. Sage Focus Editions, 154, 136-136

[41] Kline, R. B. (2005) Principles and Practice of Structural Equation Modeling ( $2^{\text {nd }}$ ed) New York: Guilford Press 